\title{
Using and Trusting in Media, Type of Governance and the Political Trust of University Students: A Case Study
}

\author{
Jahangir Jahangiri ${ }^{1} \&$ Khalil-Allah Sardarnia ${ }^{2}$ \\ ${ }^{1}$ Faculty of Social Sciences, Shiraz University, Eram Place, Shiraz, Fars, Iran \\ ${ }^{2}$ Faculty of Law and Political Sciences, Shiraz University, Eram Place, Shiraz, Fars, Iran \\ Correspondence: Jahangir Jahangiri, Department of Sociology and Social Planning, Faculty of Social Sciences, \\ Shiraz University, Eram Place, Shiraz, Fars, Iran. Tel: 989-1-7118-4112, E-mail: jjahangiri@g mail.com
}

Received: June 14, 2016 Accepted: June 29, 2016 Online Published: July 31, 2016

doi:10.5539/jpl.v9n6p20 URL: http://d x.doi.org/10.5539/jpl.v9n6p20

\begin{abstract}
Political trust in governments and political organs is a significant determinant of legitimacy. This quantitative study, using survey and questionnaire, has studied and investigated the effects of two variables of the state's governing method and performance, as well as soft power on students' political trust. The sample of the study included 400 bachelor's and master's students studying at Shiraz University. The result revealed a positive relationship students' use of domestic media and trusting their contents and their political trust on the government and the political institutions. There was a negative and inverse relation when it came to the Internet and satellite channels. In terms of government performance indicators (including sense of security, notion of rule of law, services, accountability and political effectiveness) and political trust, a positive relationship was observed. However, an inverse and significant relationship was seen between the thought that there's discrimination and corruption and political trust. The multivariate analysis showed that the variables namely Trust in news of local media, notion of corruption in institutions, notion of accountability, responsibility and supervision in the government and administration, sense of security, notion of rule of law, and sex (being man), totally explained $49.7 \%$ of changes in political trust.
\end{abstract}

Keywords: soft power, governance, political trust, state and political institutions, Shiraz University

\section{Introduction}

Trust is the pivot and the essence of social capital, whose extrinsic components are social and voluntarily civil networks, also participation and cooperation are the warp and woof of these networks. Political trust is one of the significant components of political legitimacy. The present age is the age of information explosion and global village, and citizens amply enjoy political and social awareness. As a result, the states are intensively faced with challenges and an overload of citizens' demands and criticisms. If the demands and needs are not met and responded to by the state, political legitimacy and citizens' trust in the state and ad min is trators will be damaged, probably leading to civil disobedience, movements or public protests.

Politics is now, in Castells' words, 'defined within the media space' and media have a highly symbolic power in shaping public opinions, attitudes and faith, as well as civil and political behaviors. In the same token, political trust can be influenced variably by the same factor in various political constructs and countries. Of course, the extent of media influence, particularly transnational and cyber media is different, depending on the quality of governance (good or bad) and the output of government performance, admin is trations and governing institutions . Because of Iran's political attitudes in foreign policy in recent decade, soft power has intensified more than before through the Internet, satellites and cyber space against Islamic Republic of Iran.

\section{Review of Literature}

In Persian studies done in this regard, we can point to Seyyed Emami and Montazeri Ghaem (2011), "The role of the culture of trust and performance of the political institutions in creating political trust". They have studied political trust under the frame work of cultural and institutional theoretical approach. In their studies, institutional theories, i.e. performance of institutions, have had stronger influence and role in political trust of Tehran university students than cultural theories, i.e. culture of trust. In a quantitative study, Sardarnia and Ghodrati (2008) investigated the influence of social capital and good governance on citizens' trust in Mashhad and 
Sabzevar. The findings of their multivariate testing suggests that variables related to good governance are better indicators of the variance of political trust than variables related to social capital.

In non-Persian literatures and articles on political trust Schoon \& Chen's work (2011) "Determinants of Political Trust" is noteworthy. In a longitude study throughout the life, these researchers quantitatively studied the effect of adulthood experiences in relation to their encounter with government institutions and their performance, as well as the effect of sociability in childhood and adolescence on political trust in England. Their findings revealed strong relationship between institutions performance and political trust. The effect of sociability in the primary period of life has been proven, but not as intensive as the other variable. Using the quantitative data analyzed by other researchers, Donovan et al (2012), in their research, come to this conclusion that, due to the negative news about governments, especially corruption, the level of political trust in western countries was as low as 45 to 55 percent of the respondents. Of course, political trust was higher in the US and Den mark.

Considering all the Persian works, the researchers did not come across any independent survey or quantitative study on the effect of media power through new communication technologies therefore, this study has new contributions.

\section{Theoretical and Conceptual Framework}

\subsection{Trust and Political Trust}

Trust literally means a strong belief in the honesty and goodness of someone or something. In Oxford Dictionary, trust means "Firm belief in the reliability, truth, or ability of someone or something" (Ghodrati, 1387, p. 8). Individual and social trust is the essence and fundamental nucleus of social capital as the collective property of the society. This can be a determinant factor in political trust and citizens' and civil ins titutions' interaction with the state (Bgnasco, 2003, p. 233). Trust and building trust have been of social scientists' significant concerns for the stability and survival of peaceful social relations and the interaction between nation and state, or a society free of violence.

Political trust consists of the rate of acceptance and faith of individuals in the institutions that represent them, which in turn affects the legitimacy of the state. Decreasing trust cannot considerably weaken the political legitimacy in short term; however, it can be effective in the long run, endangering the state's legitimacy (Donovan et al, 2008, p. 1). Political trust refers to the mental orientation or direction based on individuals' assessment of the state and its performances (Schoon \& Cheng, 2011,p. 2) or it refers to citizens' confidence and faith in the accuracy of the state, institutions and admin istrations' performance and decisions. Political trust is of vertical kind and is related to the state whereas individual and social trust is of horizontal kind and parallel.

David Easton methodologically puts forward three levels of trust: 1. Trust in political society (the political unit and its constituent individuals and groups) 2 . Trust in the reg ime (the general regulation s governing it) 3 . Trust in the officials and administrators. In another classification, political trust is divided into macro level or organizational (institutions, administrations and organization) and micro level, that is, the governing officials (Seyyed Emami et al, 2011, p. 185).

\subsection{Soft Power}

Fazio defines soft power as an organized attempt in making use of psychological, political, media, and propaganda techniques and tools to have influence over states, groups and people, and subsequently make a change in attitudes, beliefs, and behaviors of citizens. In Asef's view, soft power refers to psychological, political, and intelligence gathering techniques and methods which, try to affect the trust, moods, motivation, attitudes, and emotions of people at local, national and international level and encourage them to do a specific behavior or action in favor of administrators of media soft power. Claresion also defines soft power as an organized use of media and communication to change attitudes, beliefs and motivations of audiences and create political distrust in people (Nayini, 2012, p. 143). In 250 BC, Sun Tzu while talking about soft power pointed out that "to win one hundred victories in one hundred battles is not the acme of skill. To subdue the enemy without fighting is the acme of skill" (Basiri, 2012, 155).

\subsection{Governance}

Governance is considered as a manner and nature of governance and performance outputs or outcomes, which is divided into two groups of "good and bad governing". Good governance is regarded as "efficient management of public affairs through the creation of one government and legitimate ru les to promote social values of people and groups" (Plumptre, 1999 p. 2). In all, good governance can be defined as the proper management and guidance of the society within the limits of the rule of law, logical and fair decision together with accountability and responsibility, public participation, and strategies like this. 
Good governance should be defined with regards to the indicators including rule of law, efficiency in diverse dimensions, accountability and transparency in behaviors and decisions of the government, supervision, justice and fairness, security, fair and logical distribution of the goods, essential values and services, increasing the capacity of government participation and consultations, serious decrease of corruption and discrimination in diverse dimensions (Johnson \& Minis, 2000 p.2). Good governance leads to an increase in the extent of trust in and public satisfaction with the government.

Throughout the theoretical literature of political and social sciences, social sciences in general and political trust in particu lar have been explained and analyzed in two approaches, namely historical and socio-cultural approach and institutional approach. The analysis of trust grew by the development of functionalis $\mathrm{m}$ as well as structuralis $m$ in sociology and functionalis $m$ in ethnography. Integrity and trust have been regarded as the serious and essential prerequisites of order and unity within the society. Parsons considered trust as similarity and consensus of values and attitudes in the society, which was the result of control mechanismand sociability of political and social system (Mansourian and Ghodrati, 2009, p. 194).

In cultural and commun ity-based approach, political and social trust is investigated and explained in the form of the effect of the first channels of sociability including family and school in childhood and adolescence as well as civil and voluntary social networks and institutions. Putnam and Inglehart believe that the learned and internalized attitudes and beliefs in the first stages of life last throughout the next stages and affect the political and public trust of people. These beliefs and attitudes affect the whole life and rarely change.

Institutional approach was proposed by the scholars like Rothstein, Stolle, Levi, Offe and others. In this approach, it is supposed that political trust is affected by positive performance output of government and empirical experiences of citizens concerning institutions and government administrations (Schoon \& Cheng, 2011, pp. 3-4). The higher levels of performance, accountability and responsibility in government and the lower levels of corruption are closely related to the political trust. In institutional approach, political trust results from the success and expected productivity of one government institution or satisfactory performance and trust in every institution is the result of its performance and not the cause of its formation. In this implication, political trust has a rational and utilitarian foundation based on the expectations from the government and its efficiency at political, security, economical, cultural and social levels. This approach can be generalized to the exchange theory and rational choice or place the $m$ in one frame work. In words of Levi, the impression of people regard ing the efficient political institutions is generalized to the trust affect their cooperation and interaction with the government. Government institutions are the source of generating trust in case citizens consider them trustworthy (Mansourian and Ghodrati, 2009, p. 197).

Putnam also sees a bidirectional correlation between the performance of the government and trust and civil engagement, i.e. trust and civil engagement leads to a better performance of the government in one hand and better performance of the government affects the trust and consolidation of the effective civil bonds on the other hand (Bagnasco, 2003, p.234). The generalized trust is based on the national and civil bonds in a modern society. Special and strong trust specific to premodern society is based on traditional, local and kinship bonds.

Here, the theoretical issues concerning aims, levels of threat and the sources of media soft power is briefly presented. The most important aims of media and soft power are:

1) Cultural transformation with the aim of destroying the cultural and value consensus in the society and induction of the beliefs and values of the directors of the med ia and soft power instead of the prior values;

2) Political transformation with the aim of the creation and spreading public distrust in the political system, leaders, and rendering the government inefficient at the security, services, economical and political level;

3) Public encouragement to civil disobedience and creation of subversive movements and development of an alternative good government at the same time;

4) In media soft power, the government and non-government organizers make an attempt to create a soft revolution and a soft subversion; revolution happens once people, different groups, elites and civil leaders come to the point that the present political system does not act in favor of common wealth and renders inefficient and in turn decide to overthrow the political system with the help of the leaders of the media soft power (Nay ini, 2012, p. 166).

In all, with regards to the milieu of the media war, the soft threats can be divided into three levels:

1) Strategic level: At this level, the leaders and elites of a society are targeted by the media soft power with the aim of making a change in the nature and level of normalization and legislation of the leaders and elites and weakening their will and resolution in favor of the real purposes of the directors through changing their beliefs, 
perceptions, opinions and awareness.

2) The intermediate level: At this level, the public national culture and social capital are targeted and directors of the media warfare intend to generate public distrust and disappointment towards the leaders in the nation, and in total create a schism, widening the gap between people and the government in the rival or enemy states.

3) Tactic level: This level has the lowest status in which the armed forces are targeted by the media soft power with the aim of weakening the interest of defending the country, lowering loyalty and resistance in their own front and making them dis appointed (Nayini, 2012, p. 82-83).

The most important sources of soft power in a country which can consolidate it against the media soft power as well as soft threats are as follows.

1) At social and cultural level, it includes high level of trust, moral-centris m, public responsibility, social integrity, value consensus, social capital, mass cultural production of books and movies, the dynamism of public and social culture, hope and great love for society's promotion, civil and value commitment of nation and civil institutions and the like. 2. At scientific level it includes qualitative and quantitative development of the universities, pre-university schools and colleges, high technical, scientific, technological productions, and in social sciences it includes publishing leading articles in the prestigious journals around the world, developing software and study centers, etc. 3. At political level, it includes high level of leaders and political system's legitimacy, high level of public trust in the state, high level of strategic and tactical integrity of the ruling body and the state's elites, unity and no schism between nation, civil institutions and the state, public and mass support of the state, stopping increasing power struggle in the society, observing rules of the democratic game by civil institutions and reciprocal support, continuous interactive relationships between state and civil institutions, etc. Therefore, any power having high level of soft power, in Joseph Nye's words, enjoys attractions and high effective power over the groups or target audience in the rival country.

Nye used soft power as an indirect power to refer to the attractions such as culture, values, ideology, political institutions, policies, strong leaders, information and communication and other developed and complex technologies, scientific growth and the like. Accordingly, whoever possesses the soft power has the ability to influence the faiths and to change the other's behavior without employing hard military power, semi-hard economic power and economic sanctions. He considers this an important and neglected concept in the literature of realism in international relationships (Nye, 2004, p. 18-19). Nye believes that soft power is not merely convincing or the ability to arouse people but the ability to deceive and attract (Nye, 2008, p. 74).

Information explosion has led to the intensive vulnerability and penetrability of national security and political, cultural and economic boundaries among countries. Consequently, security threats have become complicated more than before. In Martin Libicki's view, any player and power that manages to use the information and cyberspace for soft power will successfully achieve the maximum goals without bloodshed and conflict (Nourmohammadi, 2011, p. 129). Electronic med ia have now become the excellent area of politics and politics is mainly practiced in the media space. Since 1990s, new commun ication technologies have played significant role in directing beliefs, feelings and behaviors, as well as political, economic and cultural attitudes of people and groups. In other words, political games and information warfare are increasingly carried out in the media and cyberspace. The information society has created novel spaces which have intensively affected social relationships, faiths and beliefs (Sardarnia, 2007: 105).

Paul Virilio believes that new information and communication technologies try to make the virtual images stronger than the real facts. In his words, information bombs are as deadly as the atomic bombs as information bombs can destroy the social memory, established beliefs, relationships and even international society in a blink of an eye through a one-way stream of information (Nourmohammadi, 2011, p. 134).

Political trust is of those concepts that cannot be explained by one or two factors, therefore, political and social sciences researchers investigate the concept from various angles, using the correlation among different factors. The authors of this study sought to investigate students' trust in the state and governing institutions from two angles: first, the amount of media consumption and the trust in their political contents, with emphasis on the Internet and the satellites, and second, the quality of performance and the type of governance. In this study, the following hypotheses were tested:

H1: There is a relationship between students' use of information media (Information and communication technologies and local media) and political trust.

H2: There is a relationship between students' trust in the news and political analyses of information med ia and political trust. 
H3: There is a relationship between government performance (sense of social security, the thought of the existence of discrimination institutions, thought that there is corruption, thought that there exists accountability, responsibility and supervision in the government and administration, the thought of the existence of rule of law and political trust, thought of the existence of optimum services, sense of citizens' effectiveness in decision making, extent of participation in re lig ious rites and relig iou s affiliation) and students' political trust.

\section{Methodology}

The method of this study, based on the data collected and analyzed, is quantitative. To collect data survey technique was used. In other words, the researchers directly approached the respondents and asked them to fill out the questionnaires. The sample of the study was taken from all bachelor's and master's students studying at Shiraz University. The sample size of the study computed from Cochran's formu la was 400. In order to select the sample of the study cluster sampling technique was applied. The reliability of the variables under investigation was more than 0.7 and the validity of the study was determined through face validity.

\section{Results}

In this part, first the results and tables relating to the control variables are presented and subsequently the results of the hypotheses of the study are mentioned using appropriate inferential statistics.

\subsection{Demographic Variables Test}

\subsubsection{The Relationship between Gender and Political Trust}

Based on the data presented in table 1, the mean score of trust in political institutions among women (37.61) was more than that observed among men (33.75). According to the difference observed between two means, i.e. -3.91, and significant level of 0.000 with $99 \%$ confidence interval of the difference, there was a significant difference between men and women in terms of trust in political institutions. Thus, the stated hypothesis is accepted.

Table1. T-test for political trust based on gender

\begin{tabular}{lccccc}
\hline \multicolumn{1}{c}{ Gender } & $\mathbf{N}$ & Mean & Std. De viation & T & Sig. \\
\hline Male & 170 & 33.75 & 8.98 & -3.91 & 0.000 \\
Female & 222 & 37.61 & 10.12 & & \\
\hline
\end{tabular}

\subsubsection{The Relationship between the Department of the Study of the Respondents and Political Trust}

Table 2 indicates the relationship between the departments of the study of the respondents with the extent of their trust in political institutions. As shown in table 2, the highest mean of the trust was among the agricultural students (37.13) and the least was among the students of arts (29.83). Based on the F (3.78) and level of significance (0.005) computed from analysis of variance, it can be stated that the difference of mean among different faculties was significant and thus the hypothesis is accepted. Furthermore, based on variance analysis and T-test there were not any significant difference in terms of political trust between different groups of people with different level of education, place of residence, and ethnicity.

Table2. The correlations between departments of the study of the respondents and the extent of political trust

\begin{tabular}{llllll}
\hline \multicolumn{1}{c}{ Faculty } & \multicolumn{1}{c}{ Frequency } & \multicolumn{1}{c}{ Mean } & \multicolumn{1}{c}{ Std. Deviation } & F & Sig. \\
\hline humanities & 107 & 36.81 & 10.18 & & \\
engineering & 49 & 32.42 & 9.36 & 3.78 & 0.005 \\
science & 103 & 36.14 & 9.93 & & \\
agriculture & 120 & 37.13 & 9.13 & & \\
arts & 13 & 29.38 & 9.67 & & \\
\hline
\end{tabular}

\subsection{The Results of Testing the Hypotheses of the Study}

H1-1: There is a relationship between the use of Internet and political trust (trust in government and political institutions). 
Table 3 indicates the correlation between research variables and political trust. According to that there is because of the correlation of -0.05 and the level of significance of 0.324 obtained, it can be stated that there was a negative correlation between the use of Internet and political trust in states and political institutions; however, the given relationship was not statistically significant; thus the stated hypothesis is rejected. Based on the correlation of -0.21 and level of significance of 0.000 , it can be stated that there was a signific ant relationship between the use of satellite and political trust. The negative relationship between the variables indicated that the more the respondents made use of satellite, the less they trusted the political institutions.

Due to the correlation of 0.17 and level of significance of 0.001 obtained from the Pearson Correlation testing, there was a significant positive relationship between the use of local media and trust in political institutions. Due to the correlation of -0.19 and level of significance of 0.000 , there was a significant negative relationship between extent of trust in the news of Internet and satellite and political trust; the more the respondents trusted the news of Internet and satellite, the less they trusted the political institutions.

Due to the correlation of 0.57 and level of significance of 0.000 , it can be stated that there was a significant positive relationship between the extent of trust in the news of local media and political trust in states and political institutions; thus, the given hypothesis is accepted. According to the correlation of 0.45 and level of significance of 0.000 obtained, it can be stated that there was a significant and positive relationship between the sense of security and political trust in state and political institutions. Thus, the hypothesis is accepted. The positive relationship between the two variables indicated that the more they feel secure, the more they trust in political institutions.

Due to the correlation of 0.455 and level of significance of 0.000 , there existed a significant and negative between the experience of discrimination and injustice in institutions and organizations and trust in state and political institutions. The less there existed discrimination and injustice in institutions and organizations, the more people trusted the political institutions. On the contrary, the more the discrimination there was, the less people trusted the government. Due to the correlation of 0.499 and level of significance of 0.000 , there was a significant relationship between the sense of corruption and state and political institutions. The negative relationship between the two variables under investigation suggested that the less there existed the sense of corruption, the more the people's trust in political institutions would be.

Due to the correlation of 0.458 and level of significance of 0.000 , there was a significant and positive correlation between sense of accountability and supervision in the government and organizations and political trust in state and political institutions. The correlation of 0.388 and level of significance of 0.000 showed a significant relationship between the sense of existence of the rule of law and trust in political institutions. the more the sense of existence of the rule of law there was, the more they trusted the political institutions.

According to the Pearson coefficient 0.291 and level of significance of 0.000 , there was a significant and positive relationship between the sense of existence of optimu m services and trust in political institutions. Due to the correlation of 0.40 and level of significance of 0.000 , there was a significant and positive relationship between the sense of citizenship and trust in political institutions. Hence, the stated hypothesis is accepted. The positive relationship between the variables suggested that there more the sense of citizenship existed, the more people trusted in the state and political institutions. According to the correlation of 0.30 and level of significance of 0.000 , there was a significant relationship between taking part in religious rituals and trust in political institutions. 
Table 3. Pearson product-moment correlation for assessing the relationship between research variables and political trust

\begin{tabular}{lcc}
\hline & The correlations & Sig \\
\hline The use of Internet & -0.05 & 0.324 \\
The use of satellite & -0.21 & 0.000 \\
The use of local med ia & 0.17 & 0.001 \\
the extent of trust in the news of Internet and satellite & -0.19 & 0.000 \\
the extent of trust in the news of local media & 0.57 & 0.000 \\
The sense of security & 0.45 & 0.000 \\
The experience of discrimination and in justice in institutions and organizations & -0.455 & 0.000 \\
The sense of corruption & -0.499 & 0.000 \\
The sense of accountability and supervision in the government and organizations & 0.458 & 0.000 \\
The sense of existence of the rule of law & 0.388 & 0.000 \\
The sense of existence of an optimu m services & 0.291 & 0.000 \\
the sense of citizenship & 0.40 & 0.000 \\
The extent of political trust & 0.30 & 0.000 \\
\hline
\end{tabular}

\section{Regression Analysis}

Multivariate analysis

Six variables including Trust in news of local media, notion of corruption in institutions, notion of accountability, responsibility and supervision in the government and administration, feeling secure, notion of rule of law, and sex (being man), have been entered multiple regression equation. $\mathrm{R}^{2}$ values fro $m$ the first to 6th stage show that, with the arrival of each variable in the regression equation at each stage, how much the dependent variable was explained. $\mathrm{R}^{2}$ value at the fifth stage shows that these six variables were able to collectively explain $49.7 \%$ of the changes in the dependent variable namely political trust. $\mathrm{R}^{2}$ in the first step shows that the variable namely Trust in news of local media alone has accounted for 31 percent of the dependent variable. $T$ values and significance levels show that, at all of the six stages, the relationship between variables entered into the regression equation and the dependent variable of political trust is significant at $95 \%$ level. The data also show that, in the second and 6th stage, the correlation between the independent variables namely notion of corruption in institutions and sex (being man) and the dependent variable is negative.

Table 4. Stepwise multivariate analysis to predict the dependent variable (political trust)

\begin{tabular}{ccccccc}
\hline Stage & Entered Variable & $\mathbf{R}$ & $\mathbf{R 2}$ & Beta & T & Sig \\
\hline $1^{\text {st }}$ & Trust in news of local media & 0.55 & 0.31 & 0.55 & 125 & 0.000 \\
$2^{\text {nd }}$ & $\begin{array}{c}\text { notion of corruption in institutions } \\
\text { notion of accountability, }\end{array}$ & 0.65 & 0.41 & -0.36 & -8 & 0.000 \\
& $\begin{array}{c}\text { responsibility and supervision in the } \\
3^{\text {rd }}\end{array}$ & 0.67 & 0.45 & 0.21 & 4.53 & 0.000 \\
$\quad$ & government and administration \\
$4^{\text {th }}$ & $\quad$ feeling secure & 0.69 & 0.47 & 0.17 & 3.7 & 0.000 \\
$5^{\text {th }}$ & notion of rule of law & 0.7 & 0.486 & 0.15 & 3.4 & 0.000 \\
$6^{\text {th }}$ & sex (being man) & 0.71 & 0.497 & -0.11 & -3 & 0.000 \\
\hline
\end{tabular}

\section{Conclusion}

Political trust in state and political institutions is one of the important prerequisites of the development in the country and achieving collective goals and one of vital determinants of political legitimacy. Ev idently, the higher the level of trust is, the more integrity and empathy between people and the govern ment is and consequently the 
more the society and government strength will be. Political trust is subordinate to important factors including performance of the government and types of governing at political, economic, socio-cultural, and security levels, nature and type of the performance of local and foreign media, etc.

In this study, the effect of two independent variables on the extent of political trust among students of Shiraz University was studied: a) media soft power and type and nature of performance of foreign media, i.e. Internet and satellite, as well as local media in terms of extent of use, content, and the extent of trust in the content presented; b) the performance of the government and form of governing together with variables including sense of security, rule of law, sense of nondiscrimination, sense of citizenship and efficacy and etc on the dependent variable of political trust of Shiraz University students concerning the government and political institutions. The most important findings of the study are presented below.

Between the variable of using the Internet and political trust, though in Pearson Correlation testing a negative relationship existed (the negative effect of the use of Internet on the political trust), statistically the relationship was not significant. However, between the variables of using the satellite, the use of local media, the amount of trust in satellite and Internet's news and extent of trust in local media with the trust in the state and political institutions, an inverse, a positive, an inverse and a negative, and a positive relationship was found respectively.

The increased use of satellite is accompanied with a decline in political trust which according to Paul Virilio's theory and by considering the content of satellite programs it can be said that these programs can change the established beliefs (here political trust) and trust to the legitimacy and transparency of government. What is shown more in the satellite programs is the issues and problems that people face in their lives, therefore, it affects the viewer's mind in a way that their problems are not seen by political authorities of country, because they are more seen in satellite programs, so, it can lead to a decline in trusting government concerning attention to people and priority of serving them for the government. On the other hand, watching the western media programs expose people to programs with more critical look to the government which is judged and assessed based on type of policy governing the west, this is sue leads to directing people's beliefs, emotions and attitudes based on what was raised in the theoretical framework which can finally lead to the reduction in political trust. The results also show that trust to media (whether domestic or foreign) has a significant relationship with political trust. Trusting in the content of programs can lead to the fact that people accept this content as an absolute reality and the emotions and trust of whom take shape based on this understanding and acceptance of reality which can lead to the formation of low political trust regarding the trust to satellite programs.

But, the important point is that no causal relationship was found between the us e and trust to the foreign media and political trust in the regression analysis and controlling the effects of other variables (government's performance and demographic variables); as it was stressed in the introduction and theoretical foundations, the effect of media on the political trust can change following to the government's performance and this is sue is clarified in here. Therefore, the government's performance and the imagination which people have from it, is deemed very important and it can neutralize the influence of western media on the political trust. In fact, this means that despite theories regarding the effect of media, the quality of government's performance limits the absolute accuracy of these theories. Finally, in this connection, it seems that it is decisive for the government to improve its real performance.

In assessing the relationship between the variables of the form of governing and the performance of the government with the political trust in political institutions, a positive relationship was seen between its sub-variables like the sense of security, the sense of being a rule of law, regulation-centrism, the sense of citizenship and efficacy, the sense of an optimum services, the sense of accountability and supervision of the government and taking part in religious rituals with the variable of the political trust. In other words, those respondents who had a positive outlook towards the performance of the government and the form of governing were politically trusted and subsequently the effect of media soft power on them was negative. The hypotheses relating to the sense of corruption, discrimination and lowering the levels of the trust among the students were accepted.

Four of the components related to the government's performance and the type of governance, contributed in explaining the changes in political trust. These findings are completely settled in the institutional approach which is mainly affected by positive outputs of performance and citizens' practical experiences in accordance with this political trust approach. Therefore, it can be concluded that political systems need legitimation which is gained through the political trust and therefore the best help the government can do for itself is to improve its performance to keep people's positive imag ination in this regard.

In terms of demographic variables, there found a significant relationship between gender and political trust. 
Women had a rather higher level of trust. The difference of means in the academic departments of the study concerning the level of the trust was statistically significant as well. However, the hypotheses regarding other demographic variables including ethnicity, marital status, place of residence and birth, parents' level of education, and academic degree were not accepted.

\section{References}

Bagnasco, A. (2001). Trust and Social Capital. In E. A menta, K. Nash, \& Alan Scott. MA (Eds.), The Blackwell Companion to Political Sociology. Oxford: Blackwell.

Basiri, M. A. (2012). Soft power against Islamic Republic of Iran. The Journal of Studies in Soft power, 2(5), 151-177.

Donovan, T., Denemark, D., \& Bowler, S. (2008). Trust in Government: The United States in Comparative Perspective. In T. Donovan, \& K. Hoover (Eds.), the Elements of Social Scientific Thinking. USA: Tho mson Wads wort.

Ghodrati, H. (2008). Examine the determinants of inter-generational and intra-generational social trust: A Case Study Mashhad and Sabzevar. Shiraz University, Shiraz, Iran.

Johnson, R. W., \& Minis, H., P. (1996). Toward Democratic Decentralization: Approaches to Promoting Good Governance. Research Triangle Institute.

Mansourian, M. K., \& Ghodrati, H. (2009). Social Trust and Its Determinants: The Study of Sabzevar City. The Annual Journal of Applied Sociology, 34, 189-215.

Nayini, A. M. (2012). The Principles and Fundamentals of Soft Power. Tehran: Saghi Publication.

Nourmohammadi, M. (2011). Soft Power, Cyberspace and the Security of Islamic Republic of Iran. The Quarterly Journal of Culture Strategy, 4(16), 127-145.

Nye, J., \& Joseph, S. (2004). Power in the global information age: From realism to globalization. Tehran: The Center of Strategic Studies. London: Routledge.

Nye, J., \& Joseph, S. (2008). Smart Power: A Conversation with Leadership Expert. Harvard Business Review, 86(11), 55-59.

Plumptre, T., \& Graham, J. (1999). Governance and Good Governance: International and Aboriginal Perspectives. Ottawa: Institute of Governance.

Sardarnia, Kh. (2007). The Political Effects of New Communication-Information Technologies. The Monthly Journal of Political-economic information.

Schoon, I., \& Cheng, H. (2011). Determinants of Political Trust: A lifetime learning model. Developmental psychology, 47(3), 619-631. http://d x.doi.org/10.1037/a0021817

Seyyed Emami, K., \& Montazeri Moghadam, R. (2011). The Role of the Culture of Trust and Performance of the Political Institutions in Creating Political Trust: The Study of Tehran University Students. The Journal of Political Sciences, 28(4), 189-216.

Srdarnya, K. A., Godrati, H., \& Islam, A. (2009). The Effect of Good Governance and Social Capital on the Political Trust: The Study of Mashhad and Sabzevar Cities. The Journal of Political Sciences, 5(16), 135-165.

\section{Copyrights}

Copyright for this article is retained by the author(s), with first publication rights granted to the journal.

This is an open-access article distributed under the terms and conditions of the Creative Commons Attribution license (http://creativecommons.org/licenses/by/4.0/). 